\title{
In Vitro Response of Cervical Cancer Cell Lines CaSki, HeLa, and ME-180 to the Antiestrogen Tamoxifen
}

\author{
Seija Grenman, ${ }^{1}$ Amnon Shapira, ${ }^{2}$ and Thomas E. Carey ${ }^{3}$ \\ Cancer Research Laboratory of the Department of Otolaryngology/Head and Neck Surgery, \\ University of Michigan, Ann Arbor, Michigan 48109
}

Received August 25. 1986

\begin{abstract}
The effect of tamoxifen, a nonsteroidal antiestrogenic drug, on the in vitro growth of three cell lines derived from carcinoma of the uterine cervix (HeLa, CaSki, ME-180) was studied using the breast cancer cell line MCF-7 as a tamoxifen-sensitive control. Logarithmically growing cells were fed daily with medium containing $5 \%$ dextran-charcoaltreated fetal bovine serum (D5) and $0,1,2.5,5,7.5$, or $10 \mu M$ tamoxifen. The cell number in replicate cultures was assessed every other day by cell counts. Growth inhibition was expressed as the percentage of the cell number in control cultures fed with D5. At a concentration of $5 \mu M$ tamoxifen, a clear decrease in cell proliferation, resulting in 66$74 \%$ inhibition of growth, was observed with MCF-7, HeLa, and ME-180 after 6 days of exposure to tamoxifen. Doses greater than $5 \mu M$ resulted in cytotoxicity and progressive cell luss. With the CaSki cell line, $2.5 \mu M$ lamoxifen induced more than $60 \%$ growth inhibition and $5 \mu M$ tamoxifen was cytotoxic. Tamoxifen-induced growth inhibition was reversed by removing tamoxifen from the cell cultures, and the cells resumed logarithmic growth after a lag period of 24-48 hr. MCF-7, but not the cervical carcinoma, lines required estradiol for complete and rapid recovery of logarithmic growth. Our results indicate that tamoxifen inhibits cell growth of these cervical carcinoma cell lines by a mechanism different from that in MCF-7. (c) 1988 Academic Press, Inc
\end{abstract}

\section{INTRODUCTION}

Since the initial finding of a growth inhibitory effect of antiestrogens in breast cancer tissue [1], the role of these agents in the treatment of malignant tumors arising from sex hormone-dependent tissues has been studied in numerous clinical and experimental studies. Currently, antiestrogens are widely used in breast cancer therapy [2-5], and more recently these agents have been suggested for therapy of endometrial [6-9] and ovarian cancer [10,11] as well. Carcinoma of the uterine cervix is the third most common gynecological cancer in the United

' Dr. Grenman is a visiting fellow from the Department of Obstetrics and Gynecology, The University of Turku, Turku, Finland.

${ }^{2}$ Dr. Shapira is from the Department of Otolarynology, Kaplan Hospital, Rehovot, Israel.

${ }^{3}$ Dr. Carey is the director of the Cancer Research Laboratory, Department of Otolaryngology/Head and Neck Surgery, 6020 KHRI, Box 0506, 1301 East Ann Street, The University of Michigan, Ann Arbor, Michigan 48109, and to whom correspondence should be addressed. 
States, with an incidence of 8.9 cases $/ 100,000$ [12]. Surgery and radiation therapy are effective treatment modalities for localized disease, but for patients with disseminated cancer, chemotherapy must be used. The uterine cervix is a part of the hormonally regulated female genital tract, and reports of hormonal therapy of cervical carcinoma using progesterone [13] or bromocriptine [14] have been published, but to our knowledge there are no studies dealing with the effects of the antiestrogenic agent tamoxifen on carcinoma of the uterine cervix. To determine the direct effects of tamoxifen on cervical cancer cells, the CaSki [15] ME-180 [16], and HeLa [17] cell lines were compared to the breast cancer cell line MCF7 [18] in growth experiments in vitro. MCF-7 is frequently used for studying the effects of antiestrogenic agents on growth of malignant cells in vitro [19-22] and was therefore chosen to be used as an internal positive control.

\section{MATERIALS AND METHODS}

MCF-7 is a cloned cell line that was derived from a malignant pleural effusion of a female patient with metastatic breast cancer in 1973 by Soule et al. [18]. It was obtained at passage 185 for use in our laboratory in 1981 from Dr. C. McGrath of the Michigan Cancer Foundation, Detroit, Michigan. MCF-7 has been shown to contain cytosolic estrogen, progesterone, and androgen receptors [23,24]. The ME-180 cell line was established in 1970 by Sykes et al. [16]. The CaSki cell line was established by Patillo et al. in 1974 [15] and was obtained at passage 518 from Dr. Robert Hussa in 1985. Both cell lines were derived from metastases to the bowel mesentery in patients with disseminated squamous cell carcinoma of the uterine cervix. In other studies we have shown that squamous cell carcinomas express a specific membrane antigen phenotype [25-27]. ME-180 and CaSki both express this typical phenotype (unpublished data). The HeLa cell line was established by Gey et al. in 1952 [17] from a biopsy of a primary tumor of the uterine cervix. This was an aggressive tumor as judged by the patient's clinical course and is most likely an adenocarcinoma, according to a retrospective review of the histology slides published by Jones nearly 20 years later [28]. In agreement with this possibility we found that HeLa like MCF-7 and other nonsquamous cancer lines does not express the squamous carcinoma membrane antigen phenotype [26], HeLa and ME-180 were obtained in 1978 from Dr. J. Fogh from the human tumor cell line bank at the Memorial Sloan-Kettering Cancer Center. The passage numbers in our laboratory are consecutive from the passage number listed by Fogh. However, we do not know if the passages by Fogh were since the lines were obtained at the Sloan-Kettering Laboratory or were from the time of establishment. HeLa was from a vial frozen in 1972 and labeled passage 3, and ME-180 was frozen before 1978, and marked passage 26. In this study, passages 33 and 45 of ME- 180 and passages 12 and 28 of HeLa were used. MCF-7 was used in passages 235 and 238 and CaSki was used in passages 525 and 535.

Dextran-coated charcoal treatment of fetal bovine serum. Unconjugated steroid hormones were depleted from the fetal bovine serum (FBS) used to prepare the culture media with dextran-coated charcoal (DCC) [29]. DCC was prepared by combining $5.0 \mathrm{~g}$ of charcoal (Norit A) and $500 \mathrm{mg}$ of dextran T-70 in $100 \mathrm{ml}$ of $0.14 M \mathrm{NaCl}$ with continuous stirring for at least $24 \mathrm{hr}$ at room temperature 
(charcoal-dextran ratio 10:1). The DCC suspension was incubated with the FBS in a ratio of $25 \mathrm{ml}$ DCC to $500 \mathrm{ml}$ FBS for $30 \mathrm{~min}$ at $50^{\circ} \mathrm{C}$ with continuous mixing. After incubation, the serum was clarified by centrifugation at $3000 \mathrm{rpm}$ for $15 \mathrm{~min}$. The treated serum supernatant (DCC-FBS) was sterilized by filtration $(0.22 \mu \mathrm{m})$ and was used at a concentration of $5 \%$ to supplement complete minimal essential medium (cMEM). Medium prepared in this way is referred to as D5.

Cell growth experiments. The cell lines were fed and passaged for several weeks before the experiments with complete minimal essential medium supplemented with $15 \%$ fetal bovine serum. cMEM consists of MEM containing $2 \mathrm{mM}$ glutamine, $1 \%$ nonessential amino acids, penicillin $(100 \mathrm{u} / \mathrm{ml})$, and streptomycin $(100 \mu \mathrm{g} / \mathrm{ml})$. Phenol red was also present. The cells were harvested from culture flasks by trypsinization with trypsin-EDTA solution containing $315 \mathrm{u} / \mathrm{ml}$ of tryptic activity and $0.2 M$ EDTA. The cell suspensions were washed, resuspended in cMEM prepared with 5\% DCC-FBS (D5), and counted. The cell density was adjusted to $2.5 \times 10^{4}$ cells $/ \mathrm{ml}$ in D5. Two milliliters of the cell suspension was delivered to each $35-\mathrm{mm}$ well of multiple 6-well plates for the cell growth experiments. During plating the cell suspension was frequently and thoroughly mixed to ensure a uniform cell density in each well. For each cell line, cell counts of three random wells were performed during plating to confirm the uniformity of cell distribution and to establish the actual initial number of cells plated. Multiple 6-well plates were prepared to establish replicates for each drug concentration and time point studied. The plates were kept in the incubator at $37^{\circ} \mathrm{C}$ in an air atmosphere containing $5 \% \mathrm{CO}_{2}$ and saturated with water vapor.

The cells were plated and allowed to grow for 3 or 4 days to reach the logarithmic growth phase. Thereafter the medium and the drugs were replaced daily to ensure that nutrient depletion would not be a factor affecting cell growth and that fresh and effective drug was present each day during the entire experiment.

Cell counts. Trypsinized cells were centrifugated at $1000 \mathrm{rpm}$ for $10 \mathrm{~min}$, resuspended in a known volume, and counted visually in hemacytometer chambers using trypan blue to assess viability. Cell counts from replicate wells were averaged and reported as cell number per $35-\mathrm{mm}$ well.

Drug preparation. Tamoxifen citrate (TAM), generously provided by Stuart Pharmaceuticals, Wilmington, Delaware and Huhtamaki Oy, Pharmaceuticals, Turku, Finland, was dissolved in $70 \%$ ethanol at 1000 times the highest final concentration and stored as "stock" solutions at $20^{\circ} \mathrm{C}$ until used. Estradiol (17$\beta$-estradiol, E2) was dissolved in absolute ethanol and was diluted to the appropriate final concentration with culture medium. In drug-treated and control cultures the final concentration of ethanol was always less than $0.1 \%$. Ethanol at $0.1 \%$ or less has been shown not to affect growth rate, viability, or saturation density of the cells over the duration of the experiments [30].

\section{RESULTS}

\section{Growth Inhibition}

The results of a dose-response experiment showing the growth inhibitory and cytotoxic effects of tamoxifen on the three cervical cell lines and MCF-7 are 


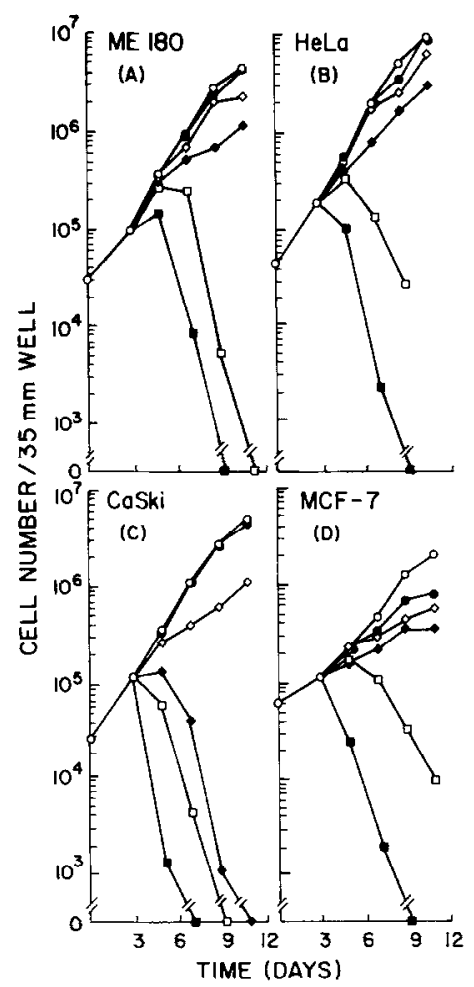

Fig. 1 Tamoxifen dose-response. Dose-response curves of ME-180, HeLa, CaSki, and MCF-7 cell lines to tamoxifen concentrations of $0(\bigcirc), 1 \mu M(\bullet), 2.5 \mu M(\diamond), 5 \mu M(\diamond), 7.5 \mu M(\square)$, and $10 \mu M(\mathbb{0})$. The control cultures were fed with culture medium D5 + ethanol as the drug solvent. Each data point is the average of three replicate wells.

shown in Fig. 1. Since the cell lines have different growth rates, the growth inhibitory effect of $1,2.5$, and $5 \mu M$ tamoxifen is shown in Fig. 2 as a percentage of control and as a function of time of exposure to tamoxifen. From these figures it is apparent that MCF-7 has the lowest threshold dose $(1 \mu M)$ for growth inhibition, which results in approximately 55\% growth inhibition by 6 days of exposure. However, at higher concentrations of tamoxifen, CaSki is the most sensitive of the four cell lines to both the growth inhibitory and cytotoxic effects of the drug. At a concentration of $2.5 \mu M$ the threshold for tamoxifen-induced growth inhibition is reached for all the cell lines tested, but at this concentration the range of growth inhibition is wide (24-77\%) (Fig.2). Thus by 6 days of exposure to $2.5 \mu M$ tamoxifen, the cell numbers of the cultures were reduced by $77 \%$ relative to control for CaSki, $65 \%$ for MCF-7, $49 \%$ for HeLa, and $24 \%$ for ME-180. With $5 \mu M$ tamoxifen comparable growth inhibition was seen in HeLa (66\%), ME-180 (74\%), and MCF-7 (72\%) cultures, whereas progressive cell loss was observed with CaSki cultures at this tamoxifen concentration. At concentrations of 7.5 and $10 \mu M$ tamoxifen, progressive cell loss and rapid decreases in cell numbers were seen in all cell lines, although there were differences in the time of exposure necessary to cause the effect (Fig.1). 


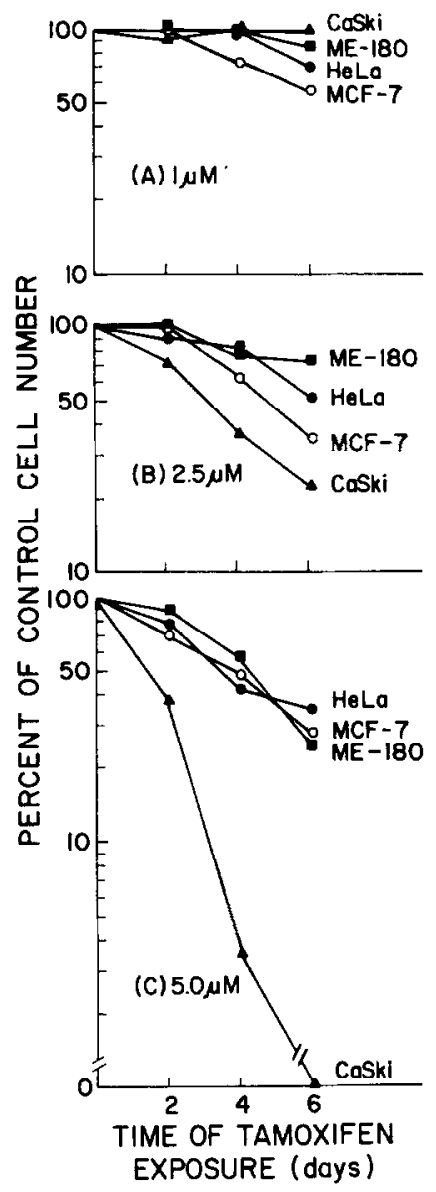

Fig. 2 Effect of tamoxifen on ME-180, HeLa, CaSki, and MCF-7 cell lines. The growth inhibitory effect of tamoxifen is given as a percentage of control (number of live cells in tamoxifen-treated cultures/number of live cells in control cultures $\times 100$ ) for three tamoxifen concentrations: (A) 1 $\mu M$; (B) $2.5 \mu M$; (C) $5 \mu M$. Each data point represents the average of three replicate wells. CaSki (A), ME-180 (ם), HeLa (๑), MCF-7 (O).

\section{Reversal of Growth Inhibition at Cytostatic Tamoxifen Concentrations}

For each cell line a characteristic concentration of tamoxifen was found at which a nearly constant cell number could be maintained for several days. This cytostatic concentration was determined for each cell line and was used to examine the reversibility of the growth inhibition phenomenon. These concentrations were 3.5 and $5 \mu M$, respectively, for CaSki and MCF-7 and 6.5 $\mu M$ for HeLa and ME-180 (Fig.3). Tamoxifen exposure was begun after the cells were in logarithmic growth on either Day 3 or 4 and continued for 3 or 4 days until cytostasis was obtained. Reversal of the tamoxifen-induced growth inhibition was then studied under three different conditions, which were (1) removal of 


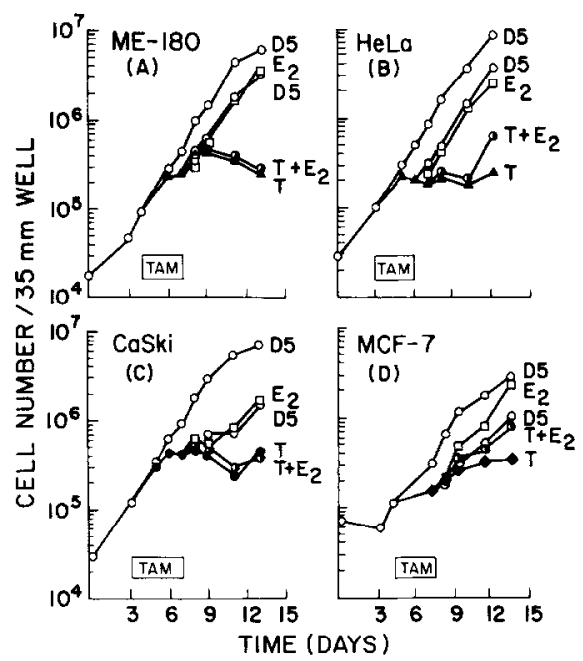

FIG. 3 Reversal of the growth inhibitory effect of tamoxifen. Cultures of ME-180, HeLa, CaSki, and MCF-7 cell lines were fed for either 3 or 4 days with tamoxifen at a concentration that caused cytostasis of each cell line. The concentrations of tamoxifen used were $6.5 \mu M(\Lambda, T)$ for ME-180 and $\mathrm{HeLa}, 3.5 \mu M(\bullet, \mathrm{T})$ for CaSki, and $5 \mu M(\diamond)$ for MCF-7. Tamoxifen-containing medium was then removed and the cultures were fed with either D5 medium containing ethanol only $(O, D 5)$; D5 medium containing tamoxifen; D5 medium containing $0.1 \mu M \quad 17-\beta$-estradiol ( $\square$, E2); or D5 medium containing both tamoxifen and $17-\beta$-estradiol $(\boldsymbol{O}), T+E 2)$ in which the tamoxifen concentrations were the same as those used to reach cytostasis and the estradiol was used at 1/50 of respective tamoxifen concentration.

tamoxifen and fecding with fresh medium alonc; (2) removal of tamoxifen and feeding with medium containing $0.1 \mu M \quad 17-\beta$-estradiol; (3) replacement of the tamoxifen by medium containing both tamoxifen and $17-\beta$-estradiol. In the latter case the $17-\beta$-estradiol was used at $1 / 50$ of the tamoxifen concentration.

The results of these experiments are shown in Fig. 3. For ME-180 and HeLa removal of tamoxifen and feeding with D5 medium resulted in recovery of logarithmic growth within $24 \mathrm{hr}$ whereas the recovery of CaSki and MCF-7 under these conditions was slower and increases in cell number were not apparent until $48 \mathrm{hr}$ after removal of the tamoxifen. Huwever, the tamoxifen-induced growth inhibition was reversible in all four cell lines and the rate of recovery seemed to be inversely correlated with the growth inhibitory effect of tamoxifen. Addition of $0.1 \mu M$ estradiol to the D5 medium did not accelerate the initial rate of recovery of any of the cervical carcinoma cell lines over that obtained with D5 medium alone. Only MCF-7 recovered more rapidly in estradiol-containing medium than in D5 medium after removal of tamoxifen. When the cultures were fed simultaneously with both estradiol and tamoxifen (at 1/50 of the tamoxifen concentration) prompt recovery from tamoxifen blockade was observed only with MCF-7. The degree of recovery was about half that obtained when tamoxifen was removed and the cells were fed with estradiol. Some recovery was also noted with HeLa, but only after several days of feeding with both drugs. 


\section{DISCUSSION}

During the past decade hormone and antihormone treatment has proven to have a role in the therapy of malignant tumors arising from hormone-dependent tissues such as breast [2-5], endometrium [6,7], ovary [10,11], and prostate [31]. Since hormonal therapy is relatively nontoxic and well-tolerated compared to other chemotherapeutic agents it is of interest to examine whether other malignant tumors are responsive to hormonal therapy as well. In recent reports the growth inhibitory effect of antiestrogens has been studied with cancer cells derived from ovary [32,33], larynx [30], other head and neck areas [34], and pancreas [35]. The uterine cervix is a part of the hormonally regulated female genital tract, yet to our knowledge there have been no studies of clinical or experimental effects of antiestrogenic agents on cervical cancer. If effective, such treatment would be a valuable addition to the therapy of advanced cervical cancer. For these reasons and because of our findings with squamous cell carcinomas of the head and neck $[30,34]$ we studied the effects of tamoxifen, a widely used nonsteroidal antihormone, on three cell lines derived from cancer of the uterine cervix. CaSki and ME-180 are well-characterized squamous carcinoma cell lines $[15,16]$ and HeLa represents adenocarcinoma of the uterine cervix [17,28], an aggressive but less common histologic tumor type at this site [36,37]. As our internal control we used MCF-7, a breast cancer cell line which is widely used for studying the growth inhibitory effects and the mechanism of action of antiestrogens [19-22]. In dose-response experiments, tamoxifen induced comparable growth inhibition in HeLa, ME-180, and MCF-7 at a concentration of $5 \mu M$ tamoxifen. The same level of growth inhibition was observed in CaSki cultures at a concentration of $2.5 \mu M$ tamoxifen, while $5 \mu M$ tamoxifen resulted in progressive cell loss. Thus, at concentrations greater than $1 \mu M$ tamoxifen, CaSki cells were more sensitive to growth inhibitory effects of tamoxifen than were MCF-7 cells which is somewhat surprising.

Results of several studies suggest that the growth inhibitory effect of antiestrogens is mediated through binding to estrogen receptors (ER) $[19-21,38]$ and so the rationale for the clinical use of these drugs has been the presence of ER in the tumors. However, the clinical correlation between ER status and response to hormonal therapy is not complete, since $25-50 \%$ of the patients having $\mathrm{ER}^{+}$ breast cancer do not respond to therapy while positive responses have been found in $10-13 \%$ or $\mathrm{ER}^{-}$cases [39-41]. Similarly, in in vitro experiments, sensitivity to the growth inhibitory effect of tamoxifen does not correlate directly with the receptor content of the tumor cells [38,42]. These observations complicate the interpretation of the mode of action of antiestrogens. The variations from the expected results could be explained either by methodological difficulties involved with steroid receptor assays and the variables that affect the expression of receptors [43] or by invoking mechanisms other than ER mediation of tamoxifeninduced growth inhibition. With regard to the first possibility, the subpopulation of MCF-7 in our use is both ER- and progesterone receptor (PgR)-positive, but in five different assays in two laboratories the cytosolic ER content has varied 
from a low value of 22 to 105 fmole/mg while $\mathrm{PgR}$ values have varied from 0 to $120 \mathrm{fmole} / \mathrm{mg}$. The variables contributing to these disparate findings appear to depend on the culture medium used, the phase of the growth curve, the density of the cells, and the laboratory that performed the receptor assay. Since these variables have been found to have striking effects on the receptor content of MCF-7, a known receptor-positive line, we are not yet certain of the receptor status of the cervical carcinoma lines used for this study. However, in three assays performed on these cells under different culture conditions, CaSki was negative for $\mathrm{ER}$ and $\mathrm{PgR}$ in all three, while $\mathrm{HeLa}$ was positive for $\mathrm{PgR}$ in one assay and ME-180 was positive for both ER and PgR in one of three assays. Thus, until culture conditions and assay conditions are optimized, we cannot rule out the possibility that the receptors are induced under certain growth conditions. With regard to the second possibility, several studies have demonstrated that cells contain antiestrogen-binding sites different from ER [38,44-46], and in cell growth experiments, failure of estradiol to reverse tamoxifen inhibition indicates that a site other than ER is important for tamoxifen-mediated growth inhibition in both $\mathrm{ER}^{+}$and $\mathrm{ER}^{-}$cell lines [30,34,42]. Furthermore, Singh et al. [47] have demonstrated that there is a difference in the chromatin acceptor sites between tamoxifen-resistant and tamoxifen-sensitive MCF-7 cell lines. Thus sensitivity or resistance to antiestrogens may depend not only on the level of receptor, but also on how the occupied receptor binds to chromatin and whether the chromatin acceptor sites for occupied receptor are available [47].

In the present analysis to study further the mode of tamoxifen-induced growth inhibition in cervical carcinoma, the cells were exposed to cytostatic concentrations of tamoxifen for 3 or 4 days after which they were released by feeding them with tamoxifen-free medium. The growth inhibitory effect of tamoxifen was reversible and not due to direct toxic effects since all four cell lines started to grow within 24 to $48 \mathrm{hr}$ after removal of tamoxifen. However, with MCF-7 only partial reversal of tamoxifen-induced inhibition was obtained unless estradiol was also added. Furthermore, simultaneous use of estradiol and a cytostatic concentration of tamoxifen resulted in partial recovery from tamoxifen blockade only in MCF-7 cultures, indicating that there was little or no competitive binding between estradiol and tamoxifen in the cervical carcinoma cultures. This observation suggests that there are differences both in the binding site (i.e., estrogen-reversible or estrogen-nonreversible) and in the mechanism of growth inhibitory effect of tamoxifen in cervical carcinoma cell lines and MCF-7. The mechanism by which tamoxifen exerts its growth inhibitory effects is unknown. Nevertheless, it is clear that these effects can occur even in the absence of detectable levels of estrogen receptor and that the effect is a reversible one.

In conclusion, we have shown that three carcinoma cell lines representing both squamous cell and adenocarcinoma of the uterine cervix exhibit antiestrogeninduced growth inhibition, which is reversible and comparable to growth inhibition achieved in MCF-7 cultures, but seems to be independent of the estrogen receptor. These results encourage us to continue preclinical studies to clarify the possible therapeutic value of antiestrogen therapy in the treatment of cervical cancer. 


\section{ACKNOWLEDGMENTS}

This study was supported by a grant from the Finnish Cancer Society, by Huhtamaki Oy, Pharmaceuticals, Leiras Medica, Turku, Finland, and by USPHS Grant No. CA 28569 from NIH-NCI. Dr. Carey is the recipient of USPHS Research Career Development Award No. CA 00621 from NIH-NCI. The authors are indebted to Donald R. Schwartz for his expert assistance and advice during this study.

\section{REFERENCES}

1. Cole, M. P., Jones, C. T. A., and Todd, I. D. H. A new anti-oestrogenic agent in late breast cancer: An early clinical appraisal of ICI 46474, Brit. J. Cancer 25, 270-275 (1971).

2. Lemer, J. J., Band, P. R., Israel, L., and Leumg, B. S. Phase II study of tamoxifen: Report of 74 patients with stage IV breast cancer, Cancer Treat. Rep. 60, 1431-1435 (1976).

3. Moseson, D. L., Sasaki, G. H., Kraybill, W. G., Leung, B. S., Davenport, C. E., and Fletcher, W. S. The use of antiestrogens tamoxifen and nafoxidine in the treatment of human breast cancer in correlation with estrogen receptor values: A phase II study, Cancer 41, 797-800 (1978).

4. Mouridsen, H. T., Elleman, K., Mattsson, W., Palshof, T., Daehnfeldt, J. L., and Rose, C. Therapeutic effect of tamoxifen versus tamoxifen combined with medroxyprogesterone acetate in advanced breast cancer in postmenopausal women, Cancer Treat. Rep. 63, 171-175 (1979).

5. Baum, M., Brinkley, D. M., Dossett, J. A., McPherson, K., Patterson, J. S., Rubens, R. D., Smiddy, F. G., Stoll, B. A., Wilson, A., Richards, D., Ellis, S. H., Controlled trial of tamoxifen as single adjuvant agent in management of early breast cancer, Lancet 1, 836-840 (1985).

6. Bonte, J., Ide, P., Billiet, G., and Wyants, P. Tamoxifen as a possible chemotherapeutic agent in endometrial adenocarcinoma, Gynecol. Oncol. 11, 140-161 (1981).

7. Hald, I. The use of tamoxifen (Nolvadex) in endometrial cancer, Rev. Endocrine-Related Cancer, Suppl. 8, 9-15 (1981).

8. Kauppila, A., and Vihko, R. Endometrial cancinoma insensitive to progestin and cytotoxic chemoptherapy may respond to tamoxifen, Acta Obstet. Gynecol. Scand. 60, 589-590 (1981).

9. Zaino, R. J., Satayswaroop, P. G., and Mortel, R. Hormonal therapy of human endometrial adenocarcinoma in nude mouse model, Cancer Res. 45, 539-541 (1985).

10. Schwartz, P. E., Maclusky, N., and Eisenfeld, A., Taxomifen therapy for advanced ovarian cancer, Proc. ASCO, Abstract 443, (1980).

11. Mycrs, A. M., Moore, G. E., and Major, F. J. Advanced ovarian carcinoma: Response to antiestrogen therapy, Cancer 48, 2368-2370 (1981).

12. Horm, J. W., Asire, A. J., Young, J. L., Jr., and Pollack, E. S. SEER Program, cancer incidence and mortality in the United States 1973-81, in NIH Publication No. 85-1837 (1984).

13. Briggs, M. H., Caldwell, A. D. S., and Pitchford, A. G. The treatment of cancer by progestogens, Hosp. Med. 2, 63-69 (1967).

14. Guthrie, D. Treatment of carcinoma of the cervix with bromocriptine. Brit. J. Obstet. Gynecol. 89, 853-855 (1982).

15. Patillo, R. A., Hussa, R., Story, M. T., Ruckert, A. C. F., Shalaby, M. R., and Mattingly, R. F. Tumor antigen and human chorionic gonadotropin in CaSki cells: A new epidermoid cervical cancer cell line, Science 196, 1456-1457 (1977).

16. Sykes, J. A., Whitescarver, J., Jernstrom, P., Nolan, J. F., and Byatt, P. Some properties of a new epithelial cell line of human origin, J. Natl. Cancer Inst. 45, 107-122 (1970).

17. Gey, G. O., Coffman, W. D., and Kubicek, M. T. Tissue culture studies of the proliferative capacity of cervical carcinoma and normal epithelium, Cancer Res. 12, 264-265 (1952).

18. Soule, H. D., Vasquez, J., Long, A., Albert S., and Brennan, M. A human cell line from a pleural effusion derived from breast carcinoma, J. Natl. Cancer Inst. 51, 1409-1416 (1973).

19. Lippman, M., Bolan, G., and Huff, K. The effects of estrogens and antiestrogens on hormone responsive human breast cancer in long term tissue culture, Cancer Res. 36, 4595-4601 (1976).

20. Katzenellenbogen, B. S. Basic mechanisms of antiestrogen action, in Hormones, receptors and breast cancer McGuire, Ed. Raven Press, New York, pp. 135-157 (1978).

21. Coezy, E., Borgna, J. L., and Rochefort, H. Tamoxifen and metabolities in MCF-7 cells: 
Correlation between binding to estrogen receptor and inhibition of cell growth, Cancer Res. 12, 264-265 (1982).

22. Sutherland, R. L., Green, M. D., Hall, R. E., Reddel, R. R., and Taylor, I. W. Tamoxifen induces accumulation of MCF-7 human mammary carcinoma cells in the GO/GI phase of the cell cycle. Eur. J. Cancer Clin. Oncol. 19, 615-621 (1983).

23. Brooks, S. C., Locke, E. R., and Soule, H. D. Estrogen receptor in human cell line (MCF-7) from breast carcinoma, J. Biol. Chem. 248, 6521-6253 (1973).

24. Horwitz, K. B., Costlow, M. E., and McGuire, W. L. MCF-7: A human breast cancer cell line with estrugen, androgen, progesterone and glucocorticoid receptors, Steroids 26, 785-794 (1975).

25. Carey, T. E., Kimmel, K. A., Schwartz, D. R., Richter, D. E., Baker, S. R., and Krause, C. J. Antibodies to human squamous cell carcinoma., Otolaryngol. Head Neck Surg. 91, 482491 (1983).

26. Carey, T. E. Establishment of epidermoid carcinoma cell lines, in Head and Neck Cancer (R. E. Wittes, Ed.), Wiley, I ondon, pp. 287-314 (1985).

27. Grossman, H. B., Wedemeyer, G., Ren, L., and Carey, T. E. UM-SCP-1, a new human cell line derived from a prostatic squamous cell carcinoma, Cancer Res. 44, 4111-4117 (1984).

28. Jones, H. W., McKusick, V. A., Harper, P. S., and Kuang-Dong, G. Wuu. The HeLa cell and a reappraisal of its origin, Cancer Res. Obstet. Gynecol. 38, 945-946 (1971).

29. Bonne, C., and Raynaud, J-P. Assay of androgen binding sites by exchange with methyltrienolone (R1881), Steroids 27, 497-507 (1976).

30. Shapira, A., Virolainen, E., Jameson, J., Ossakow, S. J., and Carey, T. E. Growth inhibition of laryngeal UM-SCC cell lines by tamoxifen: Comparison to effects on the MCF-7 breast cancer cell line, Arch. Otolaryngol. 112, 1151-1158 (1986).

31. Ekman, P., Snochowski, M., Zetterberg, A., Hogberg, B., and Gustafsson, J. A. Steroid receptor content in human prostatic carcinoma and response to endocrine therapy, Cancer 44, 11731181 (1979).

32. Lazo, J. S., Schwartz, P. E., MacLusky, N., Labaree, D. C., and Eisenfeld, A. J. Antiproliferative actions of tamoxifen to human ovarian carcinomas in vitro. Cancer Res. 44, 2266-2271 (1984).

33. Runge, H. M., Gunther, T., Neulen, J., Geyer, H., and Pfleiderer, A. In vitro responsiveness of ovarian epithelial carcinomas to endocrine therapy, Cancer Chemother. Pharmacol. 16, $58-63$ (1986).

34. Grenman, R., Virolainen, E., Shapira, A., and Carey, T. E. In vitro effects on tamoxifen on UM-SCC head and neck cancer cell lines: Correlation with the estrogen and progesterone receptor content, Int. J. Cancer 39, 77-81 (1987).

35. Benz, C., Hollander, C., and Miller, B. Endocrine-responsive pancreatic carcinoma: Steroid binding and cytotoxicity studies in human tumor cell lines. Cancer Res. 46, 2276-2281 (1986).

36. Berkowitz, R. S., Ehrmann, R. L., Lavizzo-Mourey, R., and Knapp, R. C. Invasive cervical carcinoma in young women, Gynecol. Oncol. 8, 311-316 (1976).

37. Randall, M. E., Kim, J-A, Mills, S. E., Hahn, S. S., and Constable, W. C. Uncommon variants of cervical carcinoma treated with radical irradiation, Cancer 57, 816-822 (1986).

38. Miller, M. A., and Katzenellenbogen, B. B. Characterization and quantitation of antiestrogen binding sites in estrogen receptor-positive and -negative human breast cancer cell lines, Cancer Res. 43, 3094-3100 (1983).

39. Kiang, D. T., Frenning, D. H., Goldman, A. I., Ascensaou, F., and Kennedy, B. J. Estrogen receptors and responses to chemotherapy and hormonal therapy in advanced breast cancer, N. Engl. J. Med. 299, 1330-1334 (1978).

40. Gapinski, P. V., and Donegn, W. L. Estrogen receptors and breast cancer prognostic and therapeutic implications, Surgery 88, 386-393 (1980).

41. Vollenweider-Zerargui, L., Barrclct, L. Wong, Y, LcMarchant-Bcraud, T., and Gomez, F. The predictive value of estrogen and progesterone receptors' concentrations on the clinical behavior of breast cancer in women, Cancer 57, 1171-1180 (1986).

42. Reddel, R. R., Murphy, L. C., Hall, R. E., and Sutherland, R. L. Differential sensitivity of human breast cancer cell lines to the growth inhibitory effects of tamoxifen, Cancer Res. 45, 1525-1531 (1983). 
43. Poulsen, H. S. Oestrogen receptor assay-limitation of the method, Eur. J. Cancer 17, 495-501 (1981).

44. Sutherland, R. L., Murphy, L. C., Foo, M. S., Green, M. D., and Whybourne, A. M. Highaffinity anti-oestrogen binding site distinct from the oestrogen receptor, Nature (London) 288 273-275 (1980).

45. Murphy, L. C., and Sutherland, R. L. A High-affinity binding site for the antioestrogens, tamoxifen and CI628, in immature rat uterine cytosol which is distinct from the oestrogen receptor, $J$. Endocrinol. 91, 155-161 (1981).

46. Watts, C. K. W., Murphy, L. C., and Sutherland, R. L. Microsomal binding sites for nonsteroidal anti-estrogens in MCF-7 human mammary carcinoma cells, J. Biol. Chem. 259, 4223-4229 (1984).

47. Singh, R. K., Ruh, M. F., Butler, W. B., and Ruh, T. S. Acceptor sites on chromatin for receptor bound by estrogen versus antiestrogen in antiestrogen-sensitive and -resistant MCF7 cells, Endocrinology 118, 1087-1095 (1986). 